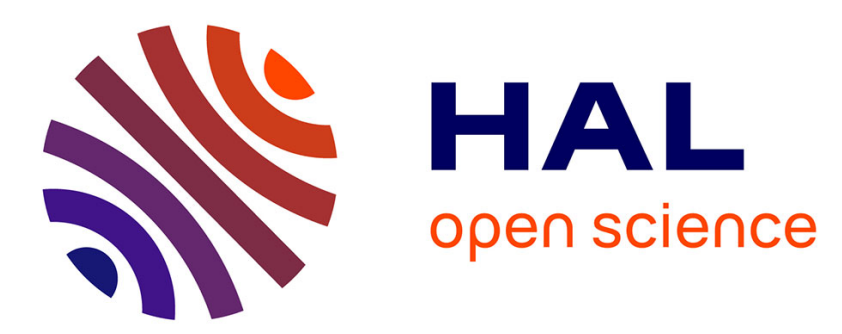

\title{
A cost estimation framework to support increased value recovery from end-of-life vehicles
}

\author{
Gareth Martin Coates, S Rahimifard
}

\section{To cite this version:}

Gareth Martin Coates, S Rahimifard. A cost estimation framework to support increased value recovery from end-of-life vehicles. International Journal of Computer Integrated Manufacturing, 2008, 21 (08), pp.895-910. 10.1080/09511920801915218 . hal-00513400

\author{
HAL Id: hal-00513400 \\ https://hal.science/hal-00513400
}

Submitted on 1 Sep 2010

HAL is a multi-disciplinary open access archive for the deposit and dissemination of scientific research documents, whether they are published or not. The documents may come from teaching and research institutions in France or abroad, or from public or private research centers.
L'archive ouverte pluridisciplinaire HAL, est destinée au dépôt et à la diffusion de documents scientifiques de niveau recherche, publiés ou non, émanant des établissements d'enseignement et de recherche français ou étrangers, des laboratoires publics ou privés. 


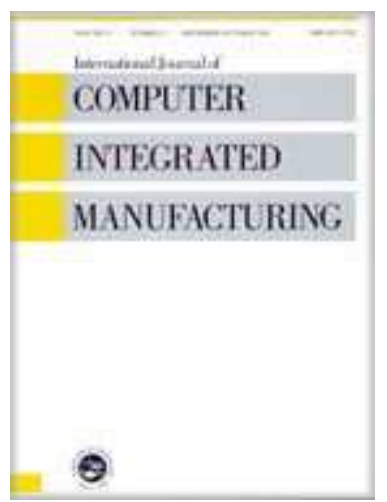

\section{A cost estimation framework to support increased value recovery from end-of-life vehicles}

\begin{tabular}{|r|l|}
\hline Journal: & International Journal of Computer Integrated Manufacturing \\
\hline Manuscript ID: & TCIM-2007-IJCIM-0101.R1 \\
\hline Manuscript Type: & Original Manuscript \\
\hline Author: & 10-Jan-2008 \\
\hline Complete List of Authors: & $\begin{array}{l}\text { Coates, Gareth; Loughborough University, Wolfson School of } \\
\text { Mechanical and Manufacturing } \\
\text { Rahimifard, S; Loughborough University, Wolfson School of } \\
\text { Mechanical and Manufacturing }\end{array}$ \\
\hline Keywords: & ENVIRONMENT, COSTING, SUSTAINABLE DEVELOPMENT \\
\hline Keywords (user): & End-of-life vehicles, Cost framework \\
\hline
\end{tabular}

\section{今 ScholarONE" \\ Manuscript Central}




\section{A cost estimation framework to support increased value recovery \\ from end-of-life vehicles}

Gareth Coates $^{a}$ and Shahin Rahimifard ${ }^{a}$

Postal address of affiliations:

${ }^{a}$ The centre for Sustainable Manufacturing and Reuse/recycling Technologies (SMART),

Wolfson School of Mechanical and Manufacturing Engineering,

Loughborough University,

Loughborough LE11 3TU,

$U K$

Corresponding author: Gareth Coates

Complete correspondence address :

The centre for Sustainable Manufacturing and Reuse/recycling Technologies (SMART),

Wolfson School of Mechanical and Manufacturing Engineering,

Loughborough University,

Loughborough LE11 3TU,

$U K$

Tel: $\quad+441509227683$

Fax: $\quad+441509227648$

Email: G.Coates@lboro.ac.uk 


\begin{abstract}
The imminent introduction of the European Directive relating to the recovery and recycling of two million end-of-life vehicles per annum has resulted in significant developments and changes within the UK vehicle recovery chain. The economic ramifications of this conformance have left many end-of-life stakeholders in a uniquely different market, based on contract negotiations, investment, and very challenging targets. The archaic and reactive nature of the recovery industry has meant that the demands of being part of the extended enterprise have never been present, and as such waste reduction and value improvement have never been major industry concerns. With the introduction of this legislation comes an increased need for the recovery chain to understand the economics of its own operations, to better support any investment or processing decisions within the new market. This paper provides an overview to the stakeholders and their relationships within the UK recovery chain, and discusses the development of an endof-life vehicle costing framework based on the current direct and indirect costs and revenues affecting vehicle retirement, to facilitate increased value recovery to an array of end-of-life operators. Each of the costing techniques adopted or developed within the framework are then further discussed, before the intended industrial applications of the framework is highlighted.
\end{abstract}

\title{
Keywords
}

End-of-life vehicles, Activity Based Costing, Cost framework, Value recovery

\section{Introduction}


The influence of European legislation is becoming progressively more prevalent within the UK, with many manufacturers and businesses becoming increasingly more accountable for their product's environmental effects beyond the traditional boundaries of the product development process. End-of-Life (EoL) disposal and product take-back legislation has taken a proactive stance and attempted to make manufacturers more environmentally aware of their producer responsibilities. EU legislation accounts for an estimated $80 \%$ of UK environmental regulations (Lowe and Ward, 1998), and has formulated a number of prescriptive directives encompassing the design, production and treatment of a range of industrial and consumer products.

One of the most widely legislated against consumer products to-date is that of the automobile through the End-of-Life Vehicle (ELV) directive. In its simplest sense the legislation requires vehicle manufacturers to provide free take-back and treatment for all its own vehicles post 2007, and meet recycling and recovery targets of $85 \%$ and $95 \%$ by 2006 and 2015 respectively. This stringent producer responsibility has also begun to envelop other product areas (waste electronics and consumer packaging), and the turbulent reform that the vehicle recovery industry is currently being subjected to will undoubtedly act as a model for these other industrial sectors.

The consumerist attitudes on which many product groups develop and grow are often mutually exclusive to the ideas of sustainability and product longevity. With the manufacturers of such products trying to achieve equilibrium between technological innovation, time-to-market and reduced costs. Stakeholders within these manufacturer's supply chains are consistently pressured to achieve higher productivity on lower profit margins, a relationship that is currently not applicable within the product recovery chain. Unlike the automotive supply chain the recovery chain is a reactive industry, able to function on uncertain return volumes and fluctuating material and part prices. Coupled with the fact that manufacturers have traditionally seen the remit of 
their responsibilities and influence ending at point of sale, the recovery industry has not seen the technical innovation, harsh competition and drive for efficiency seen within other parts of the value chain. The current transposition of the ELV directive into UK law and the establishment of manufacturer recovery networks is said to have changed this, and forced dramatic reform and investment in an otherwise archaic industry. This initial investment has therefore been undertaken through necessity rather than need, a paradigm which will ultimately change once the directive is in full operation and the dynamics of being part of the extended enterprise will envelope the product recovery sector. The stakeholders within the recovery chain will then be asking how their efforts can generate greater returns. The maximisation of a product's value at end-of-life from an economical stand point will require tools and systems to support this assessment and decision-making.

The research reported in this paper focuses on the political, environmental and economic drivers currently affecting the UK vehicle recovery sector. Once a background knowledge has been established the paper describes the various recovery costs that exist within the vehicle recovery sector, and develops a framework to map the costs of the current "as-is" recovery situation. It is argued that the identification of these end-of-life reclamation costs, combined with the disparity of interests created by the ELV Directives transpositions within the UK (between manufacturers and vehicle recovers), necessitates a re-think as to how end-of-life value is identified and exacted. The framework is therefore built around the information and tools currently available to this sector and includes techniques such as Activity Based Costing (ABC), regression analysis and time-studies. The potential benefits of increasing the transparency of stakeholder operating costs and revenues, and developing a framework that is capable of assessing end-of-life value has the potential to not only highlight the affects of current end-of-life markets on the recovery 
industry (e.g. a drop in steel prices), but can also identify areas for pro-active future investment (e.g. onsite recycling, purchase of additional equipment, etc.).

\section{The vehicle recovery chain}

Implementation of the European ELV Directive has been transposed into each of its member states in a variety of different ways. The following section looks at the stakeholders, relationships and market drivers in the context of the UK's ELV legislation. Figure 1 provides overview of the manufacturing and recovery actors and material flows through the supply and recovery chains.

\section{[Insert Figure 1]}

\subsection{Collection agents}

One of the biggest economic hurdles introduced by the ELV directive is the stipulation that last owners should be allowed to return their vehicles at no cost to themselves. Vehicle manufacturers have opted to conform to this and other legislative requirements by moving away from actively getting involved and investing in their own recovery facilities and networks, in favour of utilising the existing end-of-life actors and waste reclamation processes. This has lead to the establishment of "collection contracts", whereby third party collection agents (namely, Cartakeback and Autogreen) have agreed to administrate and fulfil the requirements laid down by the ELV directive on the vehicle manufacturer's behalf. These collection agents are charged with not only making sure each manufacturer's network has enough capacity, but also has the measures in place to meet the requirements of the directive. Between Cartakeback and Autogreen, 76 of the major vehicle brands that sell within the UK are represented (Eminton, 2007). These agents act as contact points for the vehicles last owner, and assist them in locating a 
local scrap yard and exercise their free retirement right. The rest of the actors within this section can therefore be either contracted or un-contracted to these collection agents.

\subsection{The Authorised Treatment Facility (ATF)}

The traditional idea of returning your vehicle to the local "scrappie" at the end of its life, often paying for the privilege and expecting it to degrade slowly on a piece of waste-land, is not tolerated under the new legislation. Instead, each returning vehicle must be systemically depolluted to remove the materials and fluids deemed environmentally detrimental or hazardous to the routing of the final waste stream. De-pollution typically takes between 15-30 minutes per vehicle (Coates, 2006), before the removal of any key components for resale can begin. The hulks are then compacted for ease of transportation and sold (mainly for their ferrous content) to a local shredder that often services a network of ATFs.

\subsection{The shredder facilities}

There are at present 37 shredder sites within the UK, of which 28 are located in England, five in Scotland, three in Wales, and one in Northern Ireland (Kollamthodi et al., 2003). The shredder acts as a central hub at which vehicle hulks from numerous ATFs are mixed with industrial and white goods waste streams (Ambrose et al., 2000). The shredding facilities then use rotatoryhammer mills to fragment the ferrous rich waste stream into particle sizes susceptible to magnetic (over-band magnets), density (cyclone technology) and charge (eddy current technology) separation devices. For a more detailed review of traditional sector equipment and its current implementation see Rousseau and Melin (1989), and Manouchehri (2006). These are well-established separation technologies that have high levels of throughput and automation. For example, a typical throughput rate of the hammer-mill is 150 tonnes/hour. Although well distributed in geographical location throughout the UK, many sites are united (either via 
organisation or opportunity) into shredder groups. Of the 37 shredding sites in the UK half are operated by two main organisations, namely European Metals Recycling and Sims Metal, which have been estimated to process in the region of $70 \%$ of all ELV arising (DTI, 2004). Surprisingly, despite their capacity these two main operators are not contracted to any of the collection agents. Hence, it is only the remaining shredding sites run by the independent metal merchants that provide this contracted capacity.

\subsection{The Dense-media Separation Facilities (DMS)}

Once the ferrous content has been removed, the majority of the remaining Shredder Residue (SR) is moved onto the dense-media separation facilities. These operators are mainly focused on recovering the metallic non-ferrous content from the waste, and a combination of density (floatation tanks and cyclone), charge (eddie current), volume (trommel sieving) and recognition (manual sorting, property recognition) technologies purify the waste stream. The un-removed material fraction from these facilities is currently landfilled, making this waste stream the primary focus for further recycling target improvements.

\subsection{The recovery chain and the vehicle manufacturers}

The de-pollution requirements of the directive combined with the achievement of the recycling targets have meant that the recovery sector has found itself in a unique position. Subject to a massive overhaul in its operating standards by the UK Government, they now retain the tools to carry out the requirements of the legislation (and assist the producers), but are not directly financially liable for the directives successful implementation. This has led many to believe that the only way target attainment can be guaranteed is if manufacturers take direct control of the recovery industry, and make it an integral part of their organisation. Influencing both upstream 
development and down-stream recovery. Many papers have highlighted the possibility of OEMs "vertically integrating" into the product recovery chain and the beneficial influence this would have on many of the "Design for" disciplines, but the reality of vehicle manufacturers moving away from their core competencies into an industry with a well-established experience base and infrastructure is unlikely. As such, any "design for value recovery" considered at the concept stage is currently been undertaken either due to consumer pressures, legislative requirements or corporate morality, rather than any direct end-of-life economic incentive.

\section{Review of existing ELV costing models}

End-of-life reclamation costing within the automotive sector has been researched since the early 1990's. The majority of early research was designed to support manufacturer recovery and demanufacturing activities, before moving more towards legislative conformance costing with the formulation of the ELV Directive. The shortcomings of these previous ELV modelling activities are routed in the assumption that vehicle reclamation costing directly benefits the vehicle manufacturers, hence many rely on the availability of upstream data (i.e. bills of materials for disassembly, vehicle compositions for identifying end-of-life value) to be easily transferred from vehicle designer to end-of-life recoverer. The reality that the vehicle recovery sector has been isolated by the ELV directives transposition within the UK has overridden the assertion behind much of the previous costing research (e.g. Design for Disassembly, CAD to end-of-life cost). The following section provides an overview of the previous research in this area.

\subsection{Pre-legislation vehicle reclamation costing}

Before the introduction of the ELV legislation in 2000 and the inclusion of producer responsibility, the majority of cost modelling focused on the potential value recovery 
opportunities using the existing technology and practices. One of the first pieces of costing research that specifically considered the End-of-Life automobile recovery scenarios was that produced by Diffenbach et al. (1993). Even at this early stage shredder residue was highlighted as a problematic waste stream that end-of-life operators should be focusing on, with the paper discussing the development of a "technical cost model" to assess the various recovery possibilities. Hock and Allen (1993) uniquely focused on one of these recovery scenarios (prefragmentation material recovery and recycling), considered the economic potential therein, and concluded that there was potential for value recovery if a number of issues could be overcome. The energy requirement of various automobile recovery scenarios and the subsequent economics is also discussed in Das et al. (1995). Further automobile recycling economics within the US was considered within Zamudio-Ramirez's (1996) thesis, that developed a disassembly optimisation model to facilitate pre-fragmentation value recovery. This value recovery theme is further continued within Guptas and Isaacs (1997) paper that developed "profit function" equations for both the dismantler and shredder to assess the value achievable from each disposal strategy.

\subsection{Generalised vehicle reclamation costing}

Each member state that has transposed the ELV directive has undertaken a number of economic impact assessments. This research tends to be very high-level estimating as to the economic viability of various transposition alternatives. These are not dynamic cost models and tend to provide only a momentary snapshot of the current situation. Examples of this generalised cost modelling can be seen within the François (2003) French example, Straudinger and Keoleianand (2001) US model, and Sakkas and Manios (2003) Greek case-study. Specific modelling that has considered the UK transposition can be found within Skinner and Fergusson (2003) which provides rough costings of each transposition option (i.e. last owner pays, producer pays, 
exchequer pays), and the Department of Trade and Industries full regulatory impact assessment (DTI, 2005).

\subsection{6 and 2015 target attainment costing}

To-date the majority of research regarding the economics of vehicle reclamation has been born out of a need to conformance cost current and future ELV Directive recycling and recovery targets. One of the first cost models that considered this was produced by Johnson and Wang (2002), and outlined the additional dismantling and energy recovery activities that were required to fulfil the 2006 target. One of the more controversial aspects of this paper was the detrimental economic effects that the 2015 target would have in terms of vehicle dismantling. The paper proposed that a recycling rate of $87.6 \%$ could be achieved if all 42 plastic components were removed, but this would incur a cost of $\$ 28.16$ per ELV. With the economic viability of vehicle dismantling in question, subsequent costing research focused more on the importance of high volume shredding activities. Amaral et al. (2006) modelled the effects of two different plastic separation efficiencies within the shredding process (25\% current and $40 \%$ optimised), in the hope of fulfilling the 2015 recycling target (85\%). The paper concluded that despite the improvements in plastic segregation that an optimised facility would have, additional dismantling activities would be still needed to meet the higher target; incurring plastic dismantling costs of around $43 €$ per ELV for the lower shredder efficiency (25\%), and $3 €$ per ELV for the higher (40\%). Further work produced by Ferrão et al. (2003) have developed more comparative economic analysis of dismantling versus shredding, and highlighted the effects that key factors such as vehicle composition have on dismantler and shredder profitability (Ferrão and Amaral, 2006). Ferrão et al. (2006) continue this economic modelling to incorporate the possibility of energy recovery technologies (Pyrolysis, Gasification, Co-combustion) being used 
as a means of target attainment, but concluded that traditional mechanical recycling (dismantling $\&$ shredding) offer a more realistic possibility to achieve the proposed targets.

\subsection{Future end-of-life vehicle disposal issues}

The likelihood of achieving the 2015 recycling and recovery target is further questioned in Reuter et al. (2006) who investigates the fundamental limits of ELV recycling based on an amalgamation of mechanical, feedstock and energy recovery technologies. Reuter refers to the rigid inflexibility of the current quota driven system, and the problems it will encounter as innovative light-weighting materials will result in more expensive and innovative disposal scenarios, also highlighted in Mark and Kamprath (2004). Boon et al. (2003) further considers the implications of new automobile materials of future end-of-pipe economics, and models the economics of cleaner vehicles such as electric and hybrid electric vehicles, and the resultant effects this will have on dismantler and shredder profitability. Research aimed at adapting existing recovery facilities to deal with these new types of materials in the most effective and profitable way is discussed within Williams et al. (2006). In this paper it is proposed that changes are made to the current shredding processing route based on the altering composition of ELVs. The increasing abundance of aluminium and plastics within a vehicles composition can be modelled to identify the optimum point at which shipment should occur, and how various waste streams can be banded together to improve costs. It should also be noted that this paper is one of the first instances in which environmental improvement is inferred indirectly by improving waste stream value. The optimisation of shredding activities to improve profitability is the main focus, whereas in the majority of the past literature legislative recovery targets have forcefully driven recovery activities and costing.

\section{Costs and revenues within ELV recovery}


To develop an holistic costing framework for the current vehicle reclamation industry an appreciation is needed for the different types of costs and revenues incurred. These can be broadly classified into two main groups:

- direct costs of ELV processing that are directly relatable to the activity performed, e.g. the cost of vehicle collection is directly dependent on how far the collection truck must travel.

- indirect costs of ELV processing that are not directly accountable to a specific process, e.g. the cost of heating and lighting a facility.

Direct costs and revenues are often more visible and easier to catalogue, as their links with throughput are more readily seen and understood. Component removal is an example of a direct cost as this is directly dependent on the number of sub-assemblies to be removed and the labour effort required; consequently revenue is only generated once this activity has been performed. Other more obscure direct costs and revenues are those incurred during the post-fragmentation separation of materials. Automated separation technologies can be considered as a direct revenue due to the variation in value achieved when considering different compositions of waste. The process capabilities of the equipment used within the separation activity are always static, but their effectiveness in extracting value is not. For example, consider the value-added processing of a magnetic separation device on a highly ferrous rich waste stream when compared to one composed mainly of plastics. The overall value improvement of the ferrous stream is significantly greater than that of the plastic, yet the cost of processing one tonne of waste is the same in each instance. The direct revenue from the waste stream is ultimately a function of its 
compositional contamination and pure material market value. Hence, the mixture of the waste that is placed into an automated process bears a direct relationship on its resulting value.

The other type of costs are indirect costs. These costs make a substantial contribution to the cost of processing a particular vehicle, but often trying to attribute them to a particular product or process is not straightforward. Therefore, indirect costs rely heavily on a cost estimator's ability to understand the processes and resources required to achieve a specific activity. An example within the vehicle recovery sector might be the cost incurred due to a new piece of equipment, say a vehicle de-pollution rig. The rig incurs more obvious indirect costs such as depreciation, power, maintenance, etc., which must all be absorbed and recouped by the vehicles it assists in de-polluting. Not as obvious are those other indirect costs required to have a de-pollution rig in the first place. A facility to house the rig is required (which provides heating and lighting), the rig must sit on a sealed concrete foundation (which incurs Uniform Business Rates, additional employee insurance, environmental agency site licences), the waste produced by the rig must also be managed and accounted for - the list is extensive. All these indirect costs need to be factored into the cost of processing an ELV but traditionally do not lend themselves well to straightforward product attribution. Figure 2 provides a representation of the direct and indirect costs experienced by each stakeholder and the external factors that affect their economics.

\section{[Insert Figure 2]}

\section{A framework for modelling the costs of ELV recovery}

Given the drastic reform and investment the recovery industry is currently undergoing, combined with the dependency of the sector on the long-term stability of only a few key market drivers, the future financial profitability of the sector is highly uncertain. To expect operators to make any 
commitments in the face of this uncertainty and adopt more resource intensive practices, without first giving them the ability to assess the economic feasibility of their current operations, would not promote pro-active investment. Therefore, the intension of this research is to present a collection of techniques to most effectively realise and improve EoL value. This increase in value recovery could possibly require the diversifying of an end-of-life stakeholders main core competency, or the focused improvement of existing operations. In both these instances the starting point for this economic understanding is the generation of a formulised set of costing methods most suitable to the information available and costing resolution required at end-of-life. Selection and development of these techniques is referred to as the ELV costing framework, and brings together a range of costing approaches most suitable to the end-of-life perspective of ELV recovery costing. One of the novel aspects of this framework is that it is very much based on the technical capabilities and information available to current end-of-life operators, and does not rely on substantial upstream manufacturer data and assistance.

The ELV costing framework is outlined within Figure 3, and provides an overview of the costing approaches selected to cost ELV reclamation activities within the UK. The ELV framework brings together a whole range of different costing modelling techniques, from those readily adopted within industry (i.e. Activity Based Costing), to the application of fringe techniques within this sector (i.e. parametric regression analysis), to situations in which a radically new costing approach was required all together (post-fragmentation cost modelling). The following sub-sections provide a brief insight into the main costing techniques adopted within the ELV framework. Given the diversity of costing approaches implemented within the framework the following sub-sections are intended to provide an overview as to the data collected and the techniques selected, with detailed justification, implementation and validation provided within subsequent publications. 


\section{[Insert Figure 3]}

\subsection{Data Collection Activities Relating to Framework Development}

When developing the cost estimation framework it became apparent as to the distinct lack of available end-of-life data relating to vehicle reclamation activities. Hence, a number of investigative interviews and data collection studies were undertaken that assisted in selecting the most appropriate costing approaches to be incorporated within the cost estimation framework. For a more detailed description as to how this data assisted in the selection of the various cost estimation techniques the reader is referred to Coates (2007).

\subsubsection{Industrial Interviews}

An extensive program of industrial interviews was undertaken that encompassed stakeholders throughout the vehicle value chain. These stakeholders included; (the number in brackets refers to the number of different organisations interviewed) UK policy makers (1), tier 1 suppliers (1), vehicle manufacturers (3), authorised treatment facilities (5), shredding sites (2), dense-media plants (2) and plastics re-processors (2). The majority of the output from these interviews assisted in refining the industrial focus of the research, but also highlighted the distinct lack of collaboration between various value chain stakeholders. Many were keen to share their opinions as to the current implementation ELV directive, but none were willing to share extensive vehicle manufacturing and reclamation data.

\subsubsection{Web-based Data Collection Survey}


To overcome the issues identified with missing data and to also provide a more comprehensive understanding as to the wider opinions of the pre-fragmentation sector, a set of questions were developed and distributed to over 270 ATF sites within the UK. Twenty-four sites completed the survey creating a response rate of around $8.9 \%$, which represented $2 \%$ of the UK's prefragmentation capacity (Coates, 2006).

\subsubsection{Vehicle Teardown Study}

As part of data requirements needed to select a suitable costing approach for pre-fragmentation material recycling, a dismantling study was conducted at a local ATF to generate a range of component dismantling times for a number of ELVs. These vehicles were selected based on the demographic of a natural ELV in 2006 (1993 - Astra, Escort and Fiesta), and involved the use of standard facility tools (electric screwdrivers, chisels, hammers, crowbars, etc.) to obtain the highest material yield rates possible. This data collection process identified approximately 117 individual components across the range of ELVs, while additional material separation and stripping times were also catalogued. This data was used to identify the main cost drivers within the vehicle dismantling process, and assisted in selecting an appropriate pre-fragmentation costing approach that mapped most conveniently onto these drivers.

\subsubsection{ATF Case Studies}

An IDEF0 modelling approach was adopted to provide a comprehensive snapshot of the activities undertaken at two different ATF sites within the UK. These were completed with the assistance of the operations manager's at each of the facilities and provided an effective insight 
into resources and value added processing that an ELV went through once retired. These two models subsequently formed the foundation for the selection of an indirect costing technique based on the information available and the facility manager's ability to describe their setup.

\subsection{Indirect costs}

\subsubsection{Activity-Based Costing (ABC) of end-of-life activities}

Traditional cost accounting has always attributed indirect costs using direct cost-drivers (such as labour). The inadequacies of such approaches are well documented and have lead to the development of $\mathrm{ABC}$ accounting. $\mathrm{ABC}$ assumes that activities consume resources, and as such indirect costs such as overheads and equipment depreciation can be directly linked to a machines utilisation and throughput. The effective capturing of these links (otherwise known as "costdrivers") allows the attribution of the total operating cost of an activity to unit, batch or line level quantities.

Figure 4 highlights the processing steps within the ABC methodology and its application within the development of the ELV cost model. Steps 1 and 2 require a detailed understanding of the processing stages the returning vehicle undergoes and the level of resolution that activities have to be modeled. Within the vehicle salvage industry these activities tend to be quite generic between different facilities (e.g. every facility will have a vehicle collection phase, a deregistration phase and de-pollution phase), it's the number of sub-activities associated with these phases, and the emphasis each end-of-life operator places on them, that determines the importance of these activity identification and aggregation stages within the overall $\mathrm{ABC}$ methodology. Figure 5 provides an example of this activity aggregation for a typical ATF, and 
demonstrates the different levels of resolution that each of the vehicle recovery phases can be broken down into. When developing a facility specific $\mathrm{ABC}$ model it is up to the estimator to decide on an appropriate level of activity resolution to provide a balance between modeling enough detail to capture unique activity effects while excluding those that make ineffectual contributions. An example of this would be to consider the activity of "vehicle moved for processing", identified on level 2 within Figure 5, and its subsequent sub-activities of movement and storage. Given that the resources and overheads incurred during the execution of each of these sub-activities (moving and storage) is very similar, it would be more convenient to aggregate these together and use the definition of "moved for processing" as the activity modeled. Steps 3 and 4 within ABC methodology within Figure 4 quantify the current costs of overheads and equipment investment, and attribute these to the activities that utilise them. Assessment as to the costs of facility equipment and indirect operating costs can often be a difficult and subjective exercise, hence within the methodology it is intended that the estimator specifies a range of typical values for facility equipment and overheads, and relies on the use of uncertainty modeling to correct any ambiguity in the estimators understanding before cost attribution is undertaken. It is important that this attribution of costs not only identifies the activities that consume the resources, but also apportions and weighs its influence accordingly. Step 5 requires the identification of cost-drivers that directly apply the costs to the activities. Once approximate per period quantities for these drivers have been determined, the total indirect cost for the activity can be divided by the cost-driver quantity to generate the consumption intensities (e.g. cost per unit). These consumption intensities (rates) are then used as multipliers when user defined cost-driver quantities are entered within the ELV model. A modelling consideration periphal to the $\mathrm{ABC}$ methodology, but still an integral part in terms of generating a plausable model, is that of uncertainty modelling. Work that has uniquely looked at the use of ABC within the demanufacturing process, (Bras and Emblemsvag, 1995) highlighted the need 
for the inclusion of uncertainty modelling within the method to accurately account for variations in estimated costs.

\section{[Insert Figure 4]}

\section{[Insert Figure 5]}

\subsection{Direct costs}

Direct costs within the vehicle recovery chain can significantly affect the costs of processing an individual vehicle or particular composition of waste stream. The following section provides a brief overview as to how these direct costs have been considered within the framework.

\subsubsection{Parts and material removal at the dismantling stage}

Within the current vehicle recovery chain the main emphasis has been on parts recovery and resale to generate revenues, while the dismantling of materials at the ATF stage has not been widely adopted due to the labour intensive nature of the work. The direct costs for parts and material removal are highly make and model specific, but both in different senses. Standard functional components (e.g. starter motors, radiators, wing mirrors, etc.) can always be assumed within each returning ELV, the cost is therefore a function of the placement and accessibility that varies between each instance. Where as a vehicle's removable materials composition (mainly plastics) is more often based on aesthetics as opposed to functional requirements, of which there are an inexhaustible amount of variations and possible locations within the vehicle. The costing of parts removal within the framework has therefore been considered using average removal 
times for each standard sub-assembly via a Generative-Analytical approach, where as the costing for the removal of material for recycling has required a more complex approach (Parametrics).

The International Dismantling Information System (IDIS) is a database created by a consortium of vehicle manufacturers to facilitate the dismantling of ELVs. Cataloging over 964 vehicles and over 45,000 removal materials, the system provides a comprehensive source of information as to a component's location, weight, material type and attachment. By cross-referencing a sample range of vehicles from the database with destructive tear-down data (obtained from an in-house dismantling study) approximate dismantling times can be created for a range of removable components. Using parameters available within IDIS, and knowledge from previous studies as to the parameters that affect disassembly time, a series of parametric equations were developed using multi-linear regression. These general parametric equations can then be applied to all other vehicles within the database (if the specific parameters are known for that vehicle) to generate a disassembly cost. The processing stages required for this direct costing are shown within Figure 6. For a more detailed insight into the equation development process and dismantling study data obtained the reader is referred to Coates and Rahimifard (2007).

\section{[Insert Figure 6]}

\subsubsection{De-pollution costing}

Unlike parts and materials removal the length of the de-pollution process (and hence the cost) is not directly related to manufacturer specific components on the vehicle. The time taken to pierce and drain a fuel tank is more reliant on the amount of fuel remaining in the vehicle as opposed to any make and model variations within the fuel tank's design. Factors such as the condition of the 
bolts and external locks, and the types of operations that need to be carried out on each vehicle are therefore more influential factors.

To effectively capture these cost variations, a series of time-studies were undertaken to gain an accurate representation as to the approximate times required to carry out each activity at two different ATFs, and a Generative-Analytical costing approach implemented within the framework. Potential inaccuracies within this data collection process were identified as:

- The use of non-standardised equipment and techniques at different facilities

- The varying skill levels of employees carrying out the work

- The variable degrees of effort in carrying out every de-pollution activity

\subsubsection{Post-fragmentation separation costing}

The current investment in post-fragmentation technologies by many major UK end-of-life material processors is a testament to the ever increasing demand for closed-loop resources. Currently, only high value metals are being extracted from the waste, before the remaining residue is either sold as aggregate or placed into landfill. It is envisaged that one day this residue will also be recovered, either due to legislative targets, increased landfill taxation or economic value. Industrial investment would suggest that large scale automated separation will be the preferred waste management route for many different product groups in the future. It is therefore necessary to develop ways of ascertaining the value-added these technologies achieve.

Given the range of process efficiency that exist between equipment used at different separation facilities, to accurately cost the processing capabilities of each make and model of technology is 
not practical. A theoretical separation modelling approach has therefore been proposed that can be altered to describe the separation capabilities of various automated separation technologies. It identifies which physical or material parameters each technology is trying to target within the waste stream (e.g. a floatation tank targets density, and will float all material above a certain density and sink everything else), and then utilises partition (tromp) curves to describe the processes inefficiencies. This approach allows the modelling of value-added processing operation for each post-fragmentation technology, and results in a grade and recovery percentage for each waste stream constituent. These percentages can then be cross-referenced with estimated "value vs \% contamination" curves for each material and a potential recycling revenue or disposal cost generated (see figure 7). For a more extensive insight into the application of partition curves to automated post-fragmentation material recovery the reader is referred to Coates (2007).

\section{[Insert Figure 7]}

\section{Industrial applications}

The development of an holistic costing framework mapping the processing costs within the current recovery chain has the potential to benefit multiple users. Figure 8 demonstrates some of the main functional viewpoints from the cost model and to which stakeholder within the recovery chain they relate. These potential applications are then described in the remainder of the paper.

\section{[Insert Figure 8]}

\subsection{Stakeholder cost break-down analysis}


Due to the EoL operators not having the same structure and competition present within the supply chain, the optimisation of value and the reduction of waste within the waste recovery industry has never been a major concern. The legally imposed recovery standards have changed this mentality and have meant that many stakeholders are unaware as to whether they are achieving value-for-money in terms of investment and effort. A comprehensive cost break-down analysis, although time consuming and tedious in formulation, is an integral step in EoL operators increasing the transparency and understanding of their businesses. Only then can the cause and effect implications of processing changes be truly understood.

\subsection{Service price generation}

A substantial proportion of the UK ATFs will not be contracted to a specific manufacturer, and as such are entitled to charge for the receipt of ELVs if they can guarantee the recycling and recovery targets. One of the most important questions ATF's will be asking is; how do they guarantee a stable profit when multiple factors are affecting the economics of their operation from week to week? Once a base model for a particular stakeholder within the recovery chain has been established the only significant variable costs are the prices charged for services or materials external to that stakeholder (e.g. waste management costs, shredder buy-back prices, fuel prices etc.). By only updating these specific values within the model, a very simplistic output can be generated that accounts for the fluctuations in system prices by recommendations to increase or decrease their own service charges accordingly.

\subsection{Dismantling economic assessment}


UK shredder groups are currently guaranteeing both contracted and un-contracted ATFs achievement of the 2006 recovery and recycling target $(85 \%)$ post-fragmentation. Hence, the dismantling of materials at the ATF stage is currently not a widespread practise. Given the dependency of the ATFs on the continued stability of key market drivers (i.e. the price of scrap steel) and the need to achieve a higher recovery and recycling target in 2015 (95\%), ATFs may ultimately consider the removal of materials either due to risk mitigation or target attainment.

\subsection{Value added waste-stream assessment}

As post-fragmentation separation is currently the preferred industry option for target attainment, analysis of the post-fragmentation based model can provide insight into the current limitations of the recovery facility. A more accurate understanding of the value added process improvements that each of the separation technologies has on the varying compositions of waste stream has the potential to assess and optimise the plant's layout and waste stream routing.

\section{5. "What-if” industrial scenarios}

The inclusion of new technologies or processing techniques within the model will allow the assessment of various "what-if" scenarios and provide a longer term insight into stakeholder investment and direction. This can be applied on the micro level to support a decision at each of the key stakeholders in question (e.g. the inclusion of a new plastics separation technology within the non-ferrous separation facility), or the macro level in terms of assessing fundamental changes in key market drivers (e.g. how the whole recovery industry is affected by a dramatic fall in price of scrap steel). 


\section{Concluding discussion}

The inclusion of the vehicle recovery chain within the manufacturers extended enterprise has required, and will continue to require, dramatic reform and investment in the light of current and future legislative drivers. Conformance with the directive has significantly raised the operating standards of the vehicle recovery sector, but many of the EoL operators have made this investment as a short-term fix to ensure a legitimate future within the industry. The longer term justification and payback for this continued investment, set against a backdrop of targets, manufacturer contracts and fluctuating market drivers, will ultimately require stakeholders to become leaner and achieve higher waste reduction and greater value for money. This will result in a need to more effectively understand the economics of their industry.

The effective capturing and modelling of the detailed costs and revenues presented within the vehicle recovery chain requires a systematic framework to consider both direct and indirect costs, the architecture described within this paper provides a comprehensive approach when costing this situation. The ELV costing framework presented within this paper intends to select and integrate costing techniques most suitable to the information available and resolution required, and allows various EoL operators to assess the economic ramifications of their investment and processing decisions.

The ELV costing framework has the potential to benefit multiple EoL stakeholders. The "as-is" base model can be utilised in a number of different ways. On the micro level it can support dayto-day decisions at the process level (e.g. service price generation), while at the macro level it has the potential to model fundamental shifts in key market drivers and assist the longer term strategy of EoL stakeholders. 


\section{8. $\quad$ Future Work}

The author recognises the additional areas of further work arising from the establishment of the cost estimation framework, a number of which are described below:-

\subsection{Environmental Cost Assessment of Vehicle Recovery Activities}

This estimation framework has primarily focused on the costing implications of ELV recovery. A more holistic approach to considering sustainable vehicle recovery would be to also consider the environmental impact of these activities in addition to the cost. Various tools and techniques have been developed for such environmental appraisals, which include life-cycle assessment (LCA), eco-indicators, material input per service unit and accumulative energy demand. The author proposes a future research direction to be the extension of the cost estimation framework to assess the detailed environmental implications of recycling activities.

\subsection{Industrial Validation of Post-fragmentation Modelling}

The direct costing of post-fragmentation separation activities used within the framework has developed a theoretical simulation of material separation processes. Given the lack of extensive post-fragmentation data currently collected from UK facilities the author is of the opinion that this work has significant potential to be further exploited through a comprehensive program of industrial validation exercises. Once validated for a particular facility this would generate valuable knowledge as to the best method of utilising separation technologies to most effectively 
mine the waste streams processed, and could potentially act as means of optimising a facility's setup.

\subsection{Point of Disassembly Decision Support}

Currently due to the level of customisation within vehicles there is significant variation between different makes and models in terms of sub-assemblies for resale and plastics that can be removed for recycling. One of the greatest barriers this research has identified is the distinct lack of operational support tools and available information to assist with the micro-level decisions that must be made between vehicles. Hence, a further research direction would be to investigate the application of the costing approaches discussed within the framework to most effectively integrate them into a dismantling facility's current operations.

\section{References}

Amaral, J., Ferrão, P. and Rosas, C., 2006. Is recycling technology innovation a major driver for technology shift in the automobile industry under an EU context? International Journal of Technology, Policy and Management, 6 (4), 385-398.

Ambrose, C. A., Singh, M. M. and Harder, M. K., 2000. The material composition of shedder waste in the UK. IWM Scientific and Technical Review, (November), 27-35.

Boon, J. E., Isaacs, J. A. and Gupta, S. M., 2003. End-of-life infrastructure economics for "clean vehicles" in the United States. Journal of Indusrial Ecology, 7 (1), 25-45.

Bras, B. and Emblemsvag, J., The use of activity-based costing, uncertainty, and disassembly action charts in demanufacture cost assessment, in ASME Advances in Design Automation Conference, Sept 17-20th, 1995. Boston. pp. 285-293. 
Coates, 2006. An Authorised Treatment Survey: Issues and trends within the vehicle recovery sector [online]. A report produced as part of the ESPRC project entitled cost oriented approaches to the design and recovery of vehicles by the centre for Sustainable Manufacturing and Reuse/Recycling Technologies (SMART), Loughborough, UK. Available from: www.lboro.ac.uk/smart [accessed 3rd August, 2006].

Coates, G. and Rahimifard, S., 2007. Assessing the economics of pre-fragmentation material recovery within the UK. Resources, Conservation and Recycling, Article in press, Available online 10 May 2007.

Coates, G. M., 2007. A costing framework to support a sustainable approach to end-of-life vehicle recovery. $\mathrm{PhD}$ Thesis.Loughborough University.

Das, S., Curlee, T. R., Rizy, C. G. and Schexnayder, S. M., 1995. Automobile recycling in the United States: energy impacts and waste generation. Resources, Conservation and Recycling, 14, 265-284.

Dieffenbach, J. R., Mascarin, A. E. and Fisher, M. M., 1993. Cost simulation of the automobile recycling infrastructure: The impact of plastics recovery. SAE International: Automobile life-cycle tools and recycling technology, SP-966 (930557), 45-52.

DTI, 2004. Consultation on the Transposition of Articles 5 and 7 of the End-of-Life Vehicles Directive (200/53/EC): The End-of-Life Vehicles (Producer Responsibility) Regulations 2004 [online]. URN 04/542, Available from: http://www.dti.gov.uk/files/file30649.pdf [date last accessed: 4th April 2007].

DTI, 2005. Full regulatory impact assessment (RIA) for the DTI's SI transposing articles 5 and 7 and annexes of directive 2000/53/EC of the European parliament and the council on end 
of life vehicles (the "ELV" directive) in the UK [online]. Available from: http://www.berr.gov.uk/files/file30647.pdf [Accessed 30th July, 2007].

Eminton, S., 2007. Free take-back for ELVs from 1 January 2007 [online]. http://www.letsrecycle.com/materials/metals/news.jsp?story=6394 [accessed 12th February, 2007].

Ferrão, P. and Amaral, J., 2006. Assessing the economics of auto recycling activities in relation to European Union Directive on end of life vehicles. Technological Forecasting \& Social Change, 73, 277-289.

Ferrão, P., Amaral, J. and Silva, P., Laying the foundations for a DfR tool for auto components, in 14th International Conference on Engineering Design (ICED), August 19-21, 2003. Stockholm.

Ferrão, P., Nazareth, P. and Amaral, J., 2006. Strategies for Meeting EU End-of-Life Vehicle Reuse/Recovery Targets. Journal of Industrial Ecology, 10 (4), 77-93.

François, O., Mass balance in post-shredding technology: results of a trial based on the shredding of 201 ELV's, in International Automobile Recycling Conference, 13th March, 2003, 2003. Geneva, Switzerland.

Gupta, S. M. and Isaacs, J. A., 1997. Value analysis of disposal strategies for automobiles. Computers in Industrial Engineering, 33 (1-2), 325-328.

Hock, H. and Allen, M. M. J., A preliminary study of the recovery and recycling of automotive plastics, in SAE international: International Congress and Exposition, March 1-5th 1993, 1993. Detroit, Michigan. 
Johnson, M. R. and Wang, M. H., 2002. Evaluation policies and automotive recovery options according to the European Union directive on end-of-life vehicles (ELV). Proceedings of the Institute of Mechanical Engineers Part D: Journal of Automobile Engineering, 216, 723-739.

Kollamthodi, S., Hird, A. B., Elghali, L., Johnstone, K., Wayman, M. and McColl, V., 2003. Data required to monitor compliance with the End of Life Vehicles Directive [online]. Project report PR SE/483/02 prepared for DEFRA by TRL Ltd, UK. Available from: http://www.defra.gov.uk/environment/waste/topics/elvehicles/trlstudy-one.pdf [accessed 15th March, 2005].

Lowe, P. and Ward, S., 1998. Britain in Europe: themes and issues in national environmental policy. In: Lowe, P., Ward, S., eds. British Environmental Policy and Europe. London and New York, Routledge, 326.

Manouchehri, H., R., 2006. Mapping and development of shredding product stream(s): Four shredding plants in Sweden (What should be done for better performance of the plants?) [online]. JK 88011, Northland Oretech Consulting Co. Available from: http://www.jernkontoret.se/informationsbanken/vara_publikationer/pdf_forskning/d817.p df [accessed 3rd September, 2006].

Mark, F. E. and Kamprath, A. E., End-of-life vehicle recovery and recycling polyurethance seat cushions recycling options analysis, in Product Environmental Design: Part One Recycling, Life Cycle Analysis and EcoDesign, 2004. Detroit, MI, USA.

Reuter, M. A., Schaik, A. V., Ignatenko, O. and de Haan, G. J., 2006. Fundemental limits for the recycling of end-of-life vehicles. Minerals engineering, 19, 433-449. 
Rousseau, M. and Melin, A., 1989. The Processing of Non-Magnetic Fractions from Shredded Automobile Scrap: A Review. Resources, Conservation and Recycling, 2, 139-159.

Sakkas, N. and Manios, T., 2003. End-of-life vehicle management in areas of low technology sophistication. A case study in Greece. Business Strategy and the Environment, 12, 313325 .

Skinner, I. and Fergusson, M., 2003. The implications of UK Implementation of the End-of-life Vehicles Directive [online]. Institute for European Environmental Policy Available from: http://www.euractiv.com/en/environment/implications-uk-implementation-life-vehiclesdirective/article-117335 [Accessed 20th Feb, 2007].

Staudinger, J. and Keoleian, G. A., 2001. Management of ELVs in the US [online]. CSS01-01, Center for Sustainable Systems Available from: http://css.snre.umich.edu/css_doc/CSS01-01.pdf [accessed 2nd April, 2006].

Williams, J. A. S., Wongerweragiat, S., Qu, X., McGlinch, J. B., Bonawi-tan, W., Choi, J. K. and Schiff, J., 2006. An automotive bulk recycling planning model. European Journal of Operational Research, 177 (2), 969-981.

Zamudio-Ramirez, P., 1996. Economics of Automobile Recycling. PhD Thesis.MIT. 
$\underline{\text { List of illustrations }}$

Fig. 1 The vehicle value-chain and the UK markets for components and materials recovered.

Fig. 2 The direct and indirect costs within the vehicle recovery chain

Fig. 3 Costing techniques utilised within the ELV costing framework

Fig. 4 ABC processing stages required for the estimation of indirect costs to operators within the recovery chain

Fig. 5 An example of step 2 (Activity aggregation) within the ABC methodology adopted within the framework

Fig. 6 Direct costing of materials removal at the dismantling stage and how make and model variations can be accounted for

Fig. 7 Development of a theoretical separation model to cost the recovery of post-fragmented waste streams

Fig. 8 Functional viewpoints of the application of the ELV costing framework 
Figure 1

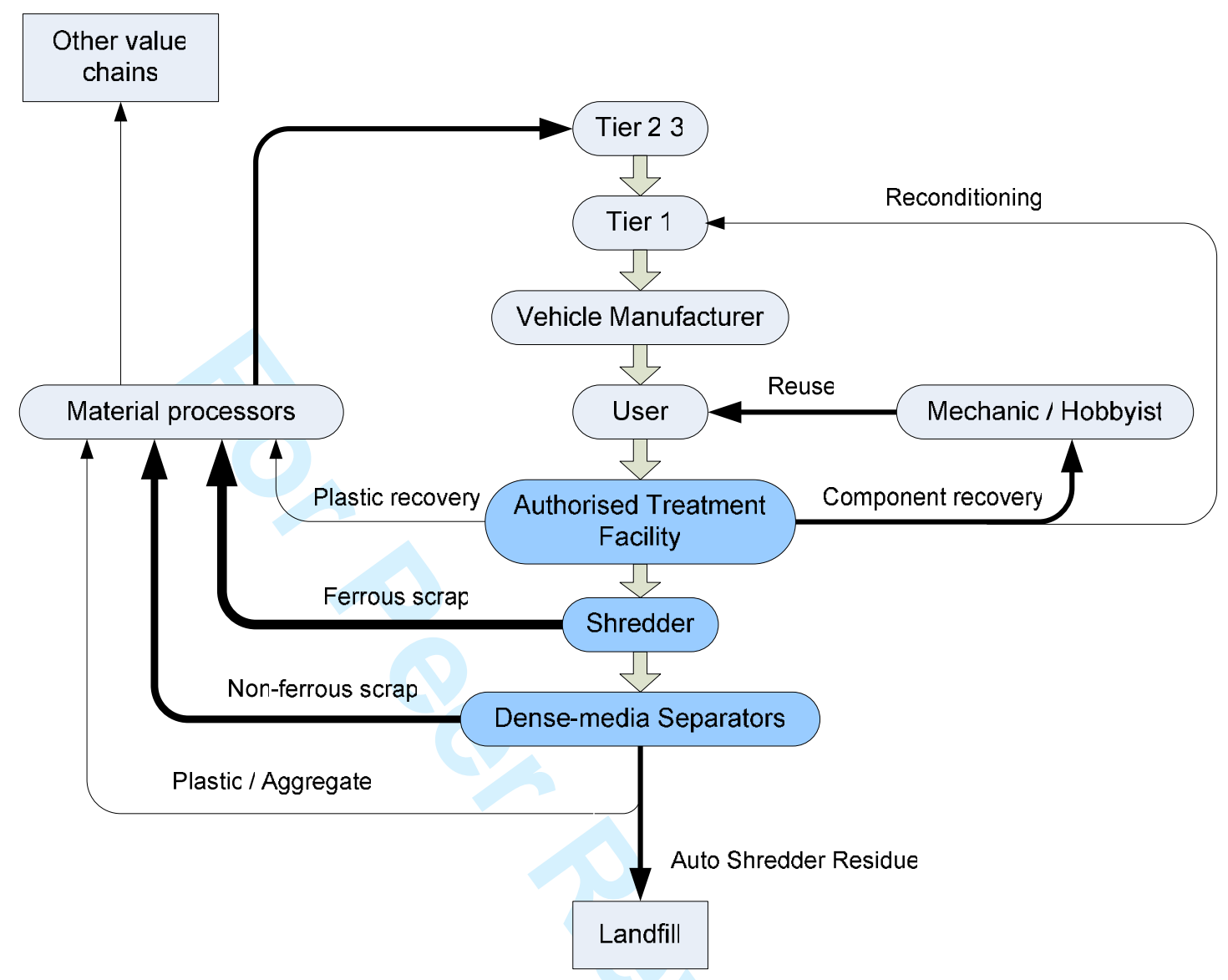


Figure 2

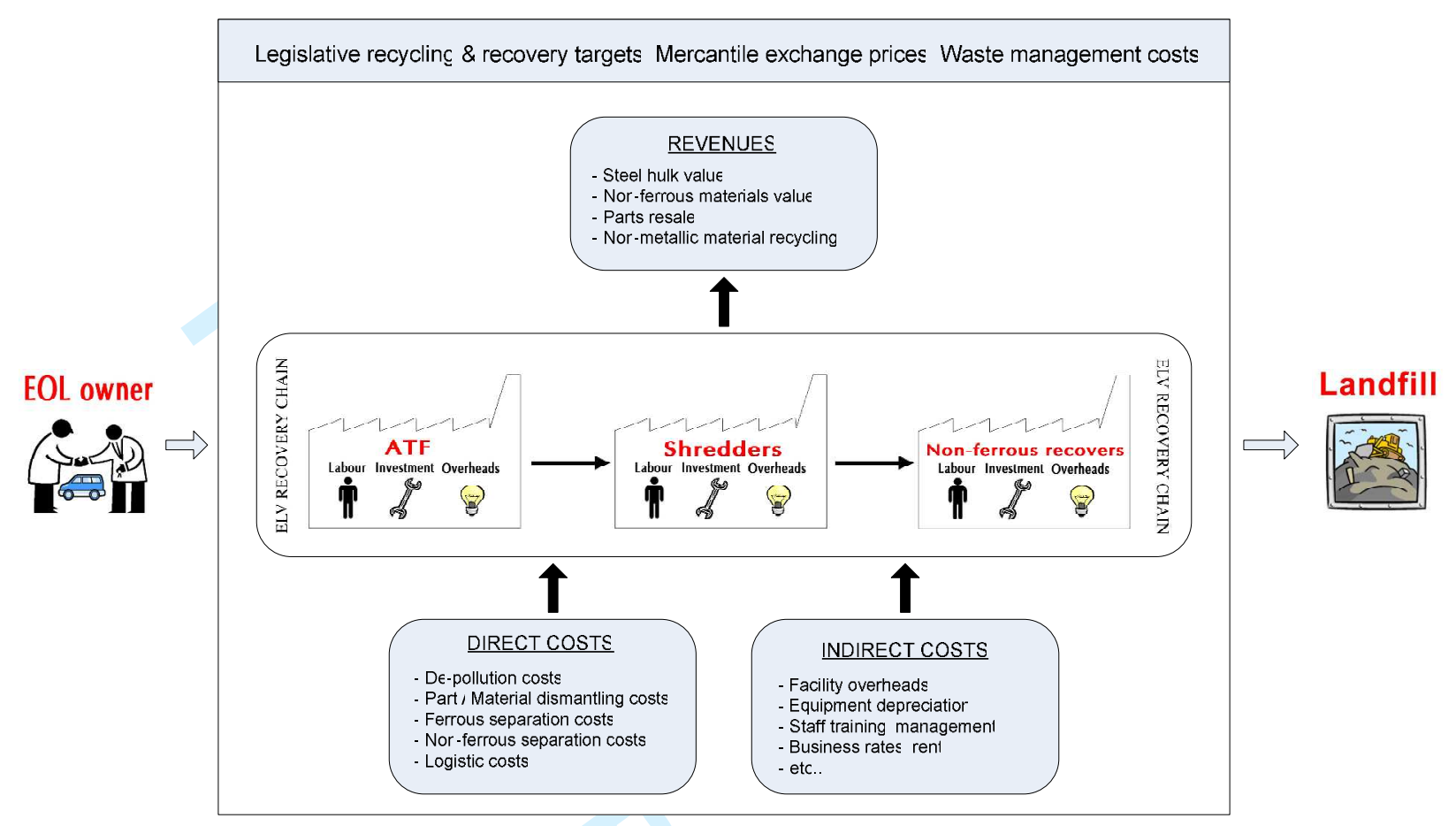


Figure 3

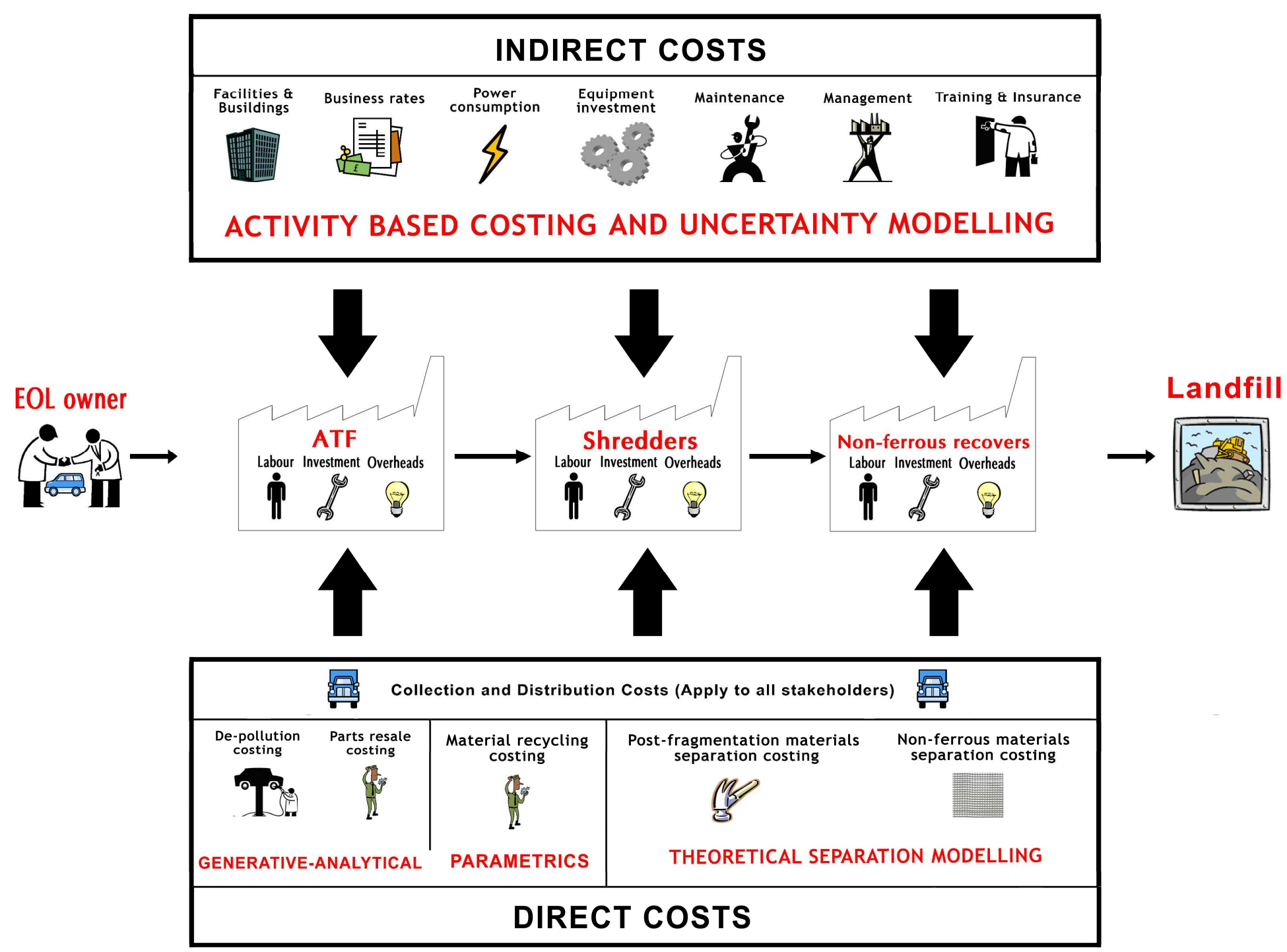

URL: http://mc.manuscriptcentral.com/tandf/tcim Email:ijcim@bath.ac.uk 
Figure 4

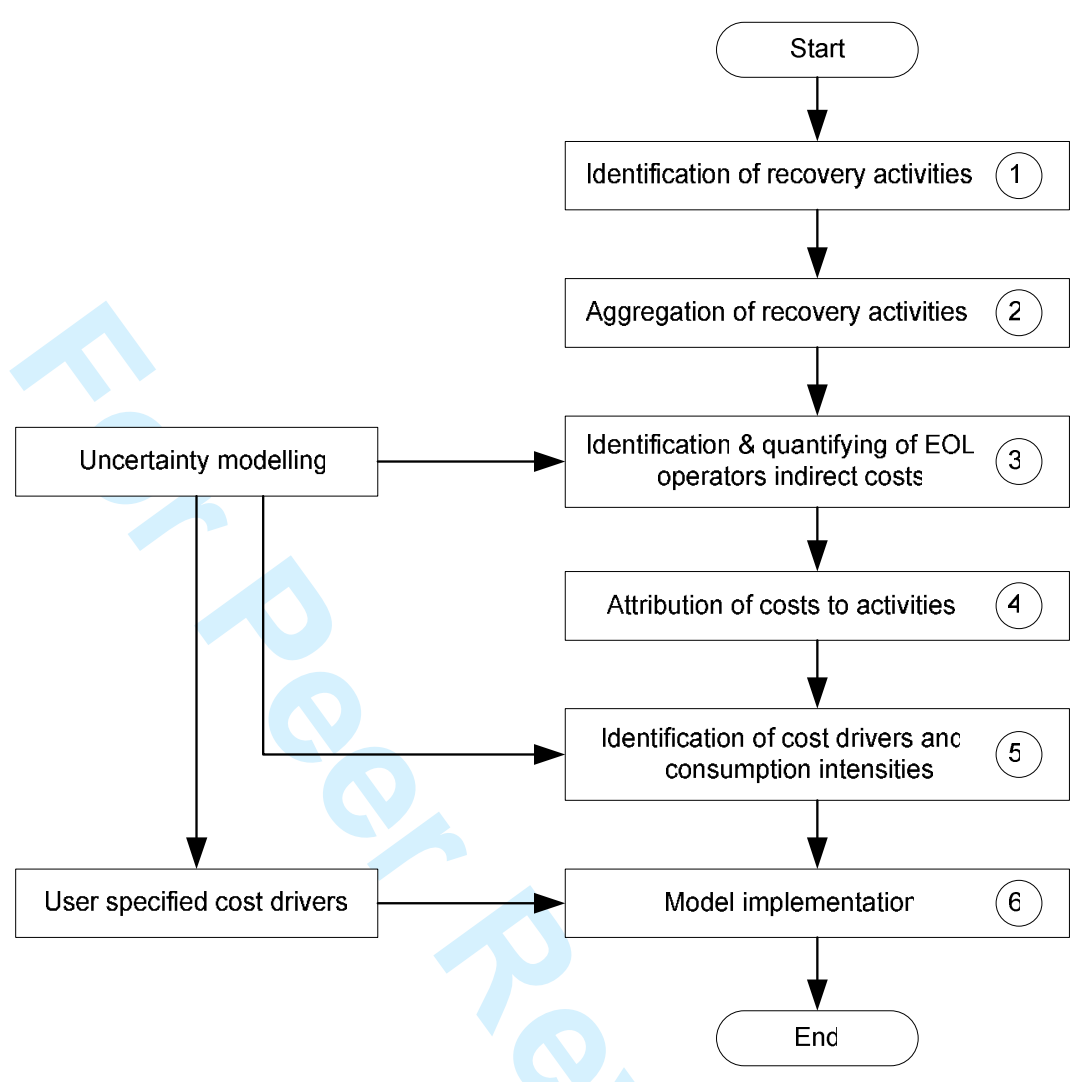


Figure 5

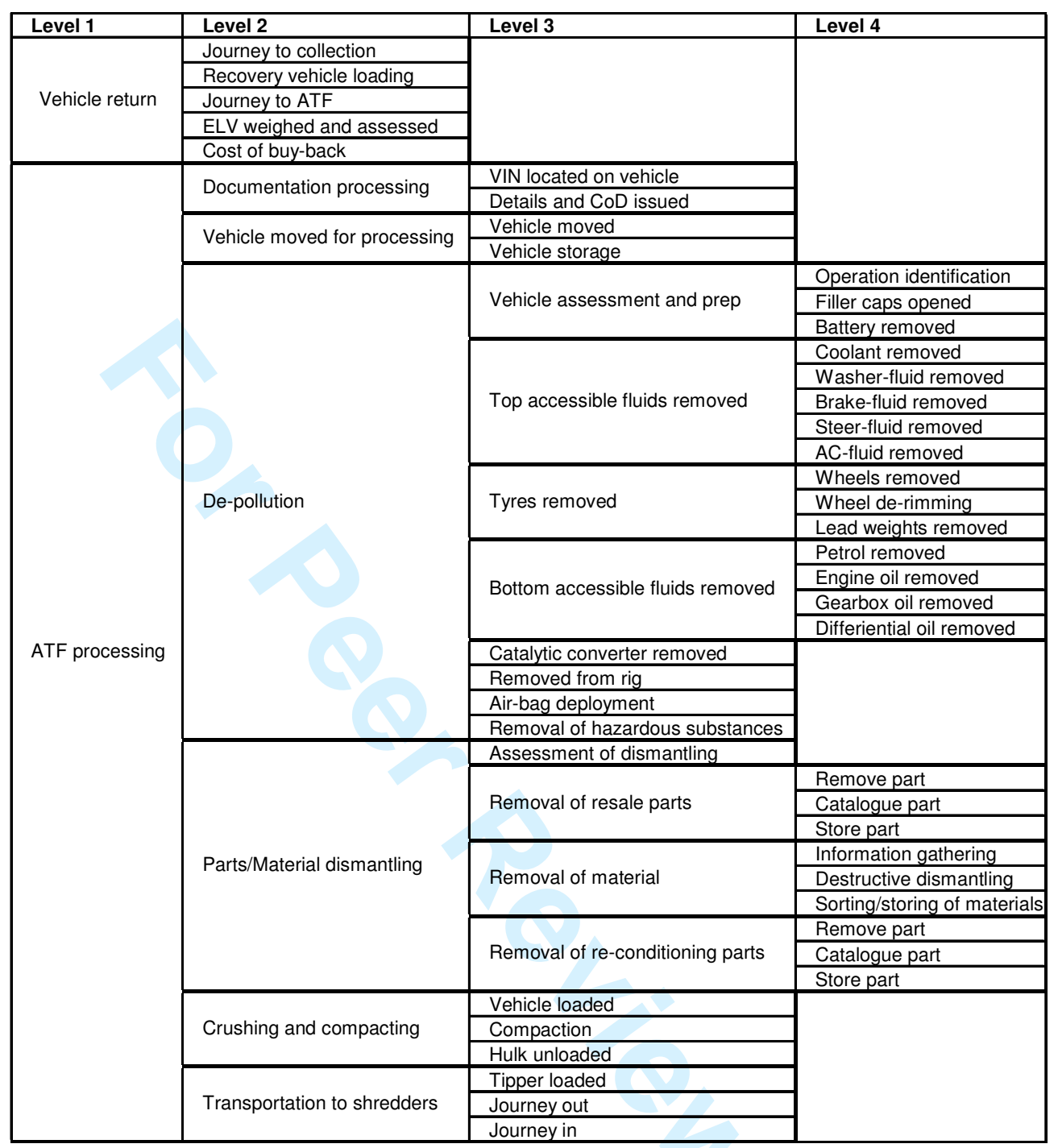


Figure 6

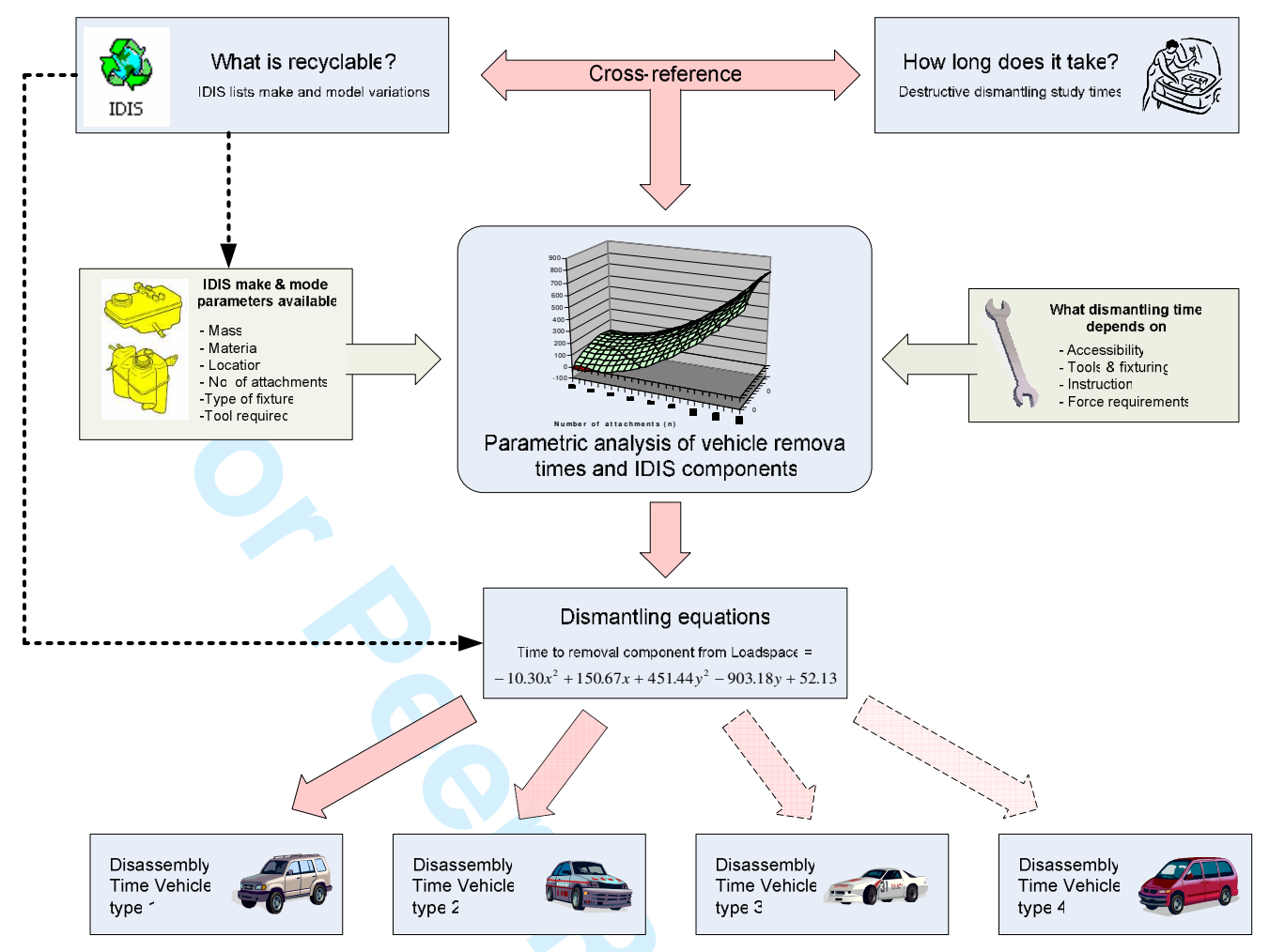


Figure 7

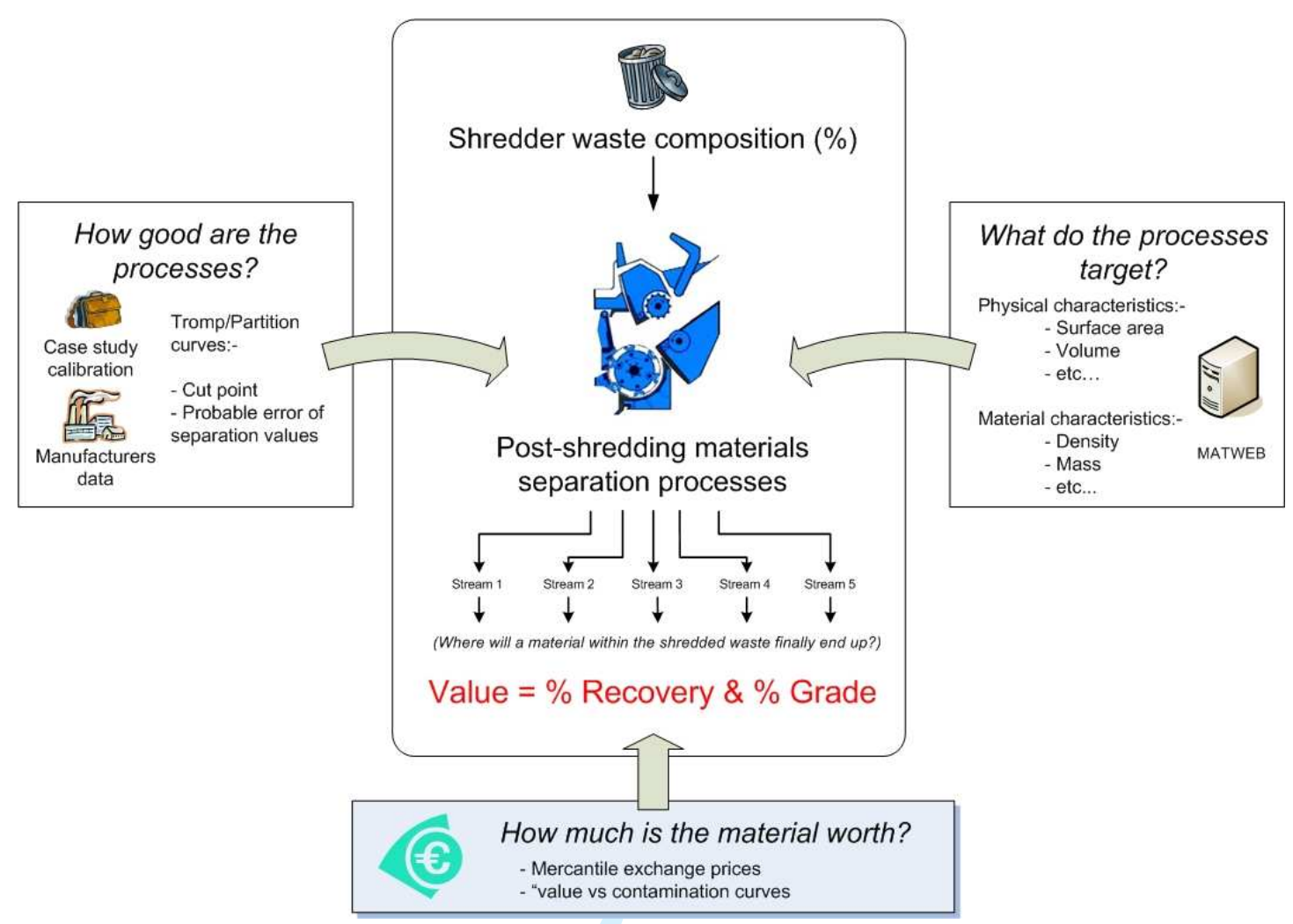




\section{Figure 8}

Stakeholder cost break-down analysis

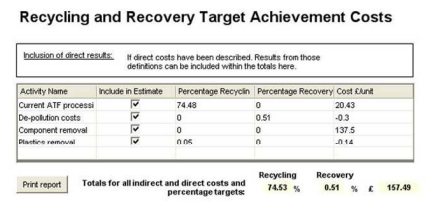

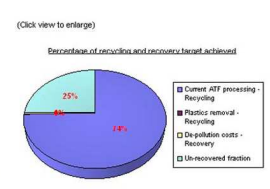

"What-if" processing scenarios
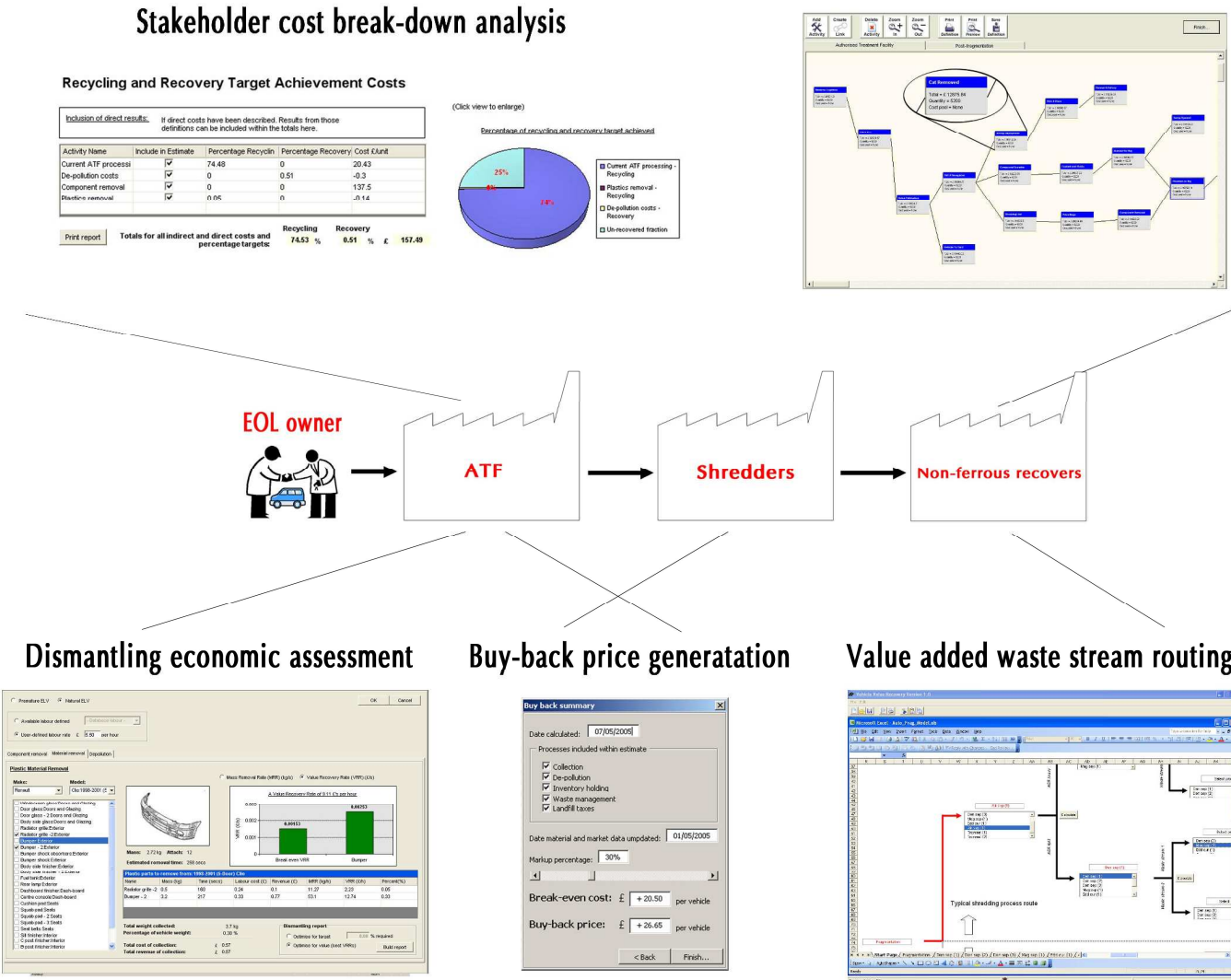

Buy-back price generatation

Value added waste stream routing
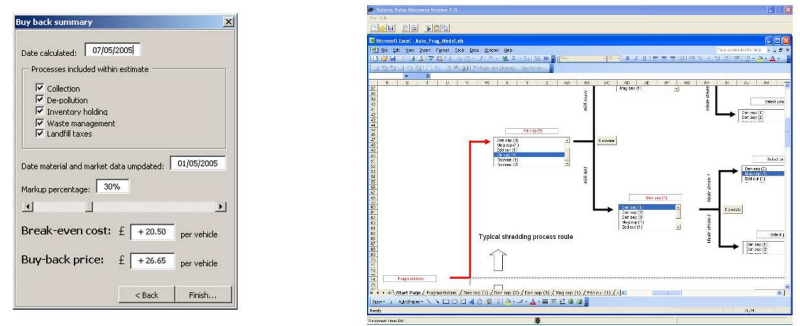